Wallas' four-stage model of the creative process: More than meets the eye?

Eugene Sadler-Smith

Surrey Business School, University of Surrey, UK

Address for Correspondence

Eugene Sadler-Smith

Professor of Organizational Behaviour

Surrey Business School

University of Surrey

Guildford GU2 7XH

UNITED KINGDOM

e.sadler-smith@ surrey.ac.uk 


\title{
Wallas' four-stage model of the creative process: More than meets the eye?
}

\begin{abstract}
Based on a detailed reading of Graham Wallas' Art of Thought (1926) it is argued that his four-stage model of the creative process (Preparation, Incubation, Illumination, Verification), in spite of holding sway as a conceptual anchor for many creativity researchers, does not reflect accurately Wallas' full account of the creative process. Instead it is suggested that a five-stage model that gives due recognition to the detailed treatment Wallas gave to the Intimation stage is a more authentic representation of his explanation of creativity. A version of this model with three levels of 'proximity to consciousness' (non-consciousness; fringe consciousness; consciousness) and five stages (Preparation; Incubation; Intimation; Illumination; Verification) is presented as a general conceptual architecture within which relevant concepts and theories from more recent creativity research, including neuroscience and intuition, are positioned and from which a number of implications are drawn.
\end{abstract}

Keywords: creativity; insight; intuition 


\section{Wallas' four-stage model of the creative process: More than meets the eye?}

\section{Introduction}

Wallas' four-stage model of the creative process consisting of "Preparation, Incubation, Illumination (and its accompaniments), and Verification" (Wallas, 1926, p.10) is foundational in creativity research. It has "shown its usefulness through years" (Runco, 2004, p.665) inspiring "hundreds, if not thousands, of spirited discussions and research projects" (Vartanian, Bristol, \& Kaufman, 2013, p.xiv). Despite being published almost nine decades ago the mode still holds sway as a conceptual anchor for many creativity researchers (e.g., Dewett, 2003; Dodds, Smith, \& Ward, 2002; Ellwood, Pallier, Snyder and Gallate, 2009; Gallate, Wong, Ellwood, Roring, \& Snyder, 2012; Healy \& Runco, 2006; Horan, 2007, 2009; Horng \& Hu, 2008, 2009; Howard-Jones \& Murray, 2003; Jalil, 2007; Kristensen, 2004; Mainmelis, 2002; Norlander \& Gustafson, 1997, 1998; Orlet, 2008; Pagel \& Kwiatkowski, 2003; Patrick, 1937; Penaloza \& Calvillo, 2012; Rastogi \& Sharma, 2010; Segal, 2004; Sio \& Rudowicz, 2007; Yeh, 2004). Although some creativity researchers have proposed finer granularities (e.g. Cropley \& Cropley, 2005, 2012; Doyle, 1998) most have adhered to the basic framework to the extent that the four-stage model has the status of shared 'in-house' assumption (Alvesson \& Sandberg, 2011) amongst creativity researchers. Given this state of affairs it is perhaps worth taking stock and examining more closely Wallas' writings in order to ask three questions: 'what did Wallas actually say?'; 'is there more to Wallas' model than meets the eye?'; and 'what are the theoretical and evidential implications of this reading of Wallas for creativity research?'

\section{What did Wallas actually say?}

Graham Wallas' (Figure 1) brief biography is as follows ${ }^{1}$ :

\footnotetext{
${ }^{1}$ http://archives.lse.ac.uk/Record.aspx?src=CalmView.Catalog\&id=COLL+MISC+0162. http://www.spartacus.schoolnet.co.uk/TUwallas.htm Accessed 30 ${ }^{\text {th }}$ January 2014
} 
Graham Wallas was born in Sunderland, England on $31^{\text {st }}$ May, 1858 and educated at Shrewsbury School and Corpus Christi College, Oxford, where he obtained a second class degree in Literae Humaniores (Classics) in 1881. He became a schoolmaster in 1884 at Highgate School, London. In 1886 he joined the Fabian Society, a UK left-leaning political 'think tank' whose members also included George Bernard Shaw and H.G Wells. He became a lecturer at the London School of Economics (LSE) in 1895, and became the LSE's first Professor of Political Science in 1914. He was described by colleagues as 'benevolent', 'kindly', and 'selfless'. Along with The Art of Thought his other books included The Great Society (1914) and Human Nature in Politics (1924). He retired from the LSE in 1923 and died in Cornwall on $9^{\text {th }}$ August, 1932.

Wallas' Art of Thought was first published in London in 1926 by Jonathan Cape. His motivation in writing the book was for "an improved art of thought" based on a "scientific explanation" of thinking (Wallas, 1926, p.7). The book is in 12 chapters. The four-stage model of creativity is presented the fourth chapter, 'Stages of Control' (pp.79-107). In order to simplify the intellectual challenge he had set himself Wallas focused on single 'achievements of thought' in order to attain clear delineation of relevant psychological events. The "single achievements" Wallas chose to concern himself with were making a "new generalization", creating a "new invention", or in the "poetical expression" of a new idea (p.79). The evidential basis of his model included the writings of Helmholtz, Poincaré and various poets. His model is rooted in the psychologies of Aristotle (p.63 of The Art of Thought), James (p.97), Dewey (p.98), Wundt (p.98), and Freud (via the now little-known Belgian psychologist Varendonck, p.67ff). The baseline assumption in Wallas' writings is that "creative thinking can be delineated" and this led him to a "four-stage description of the creative process" (Runco, 2014: p.21)

[FIGURE 1 HERE]

\section{Helmholtz and the process of scientific discovery}

Wallas was able to "dissect out" (Wallas, 1926, p.79) a tangible process of scientific discovery. He began by analyzing the speech the great German physician and physicist 
Hermann Helmholtz (1821-1884) gave at his $70^{\text {th }}$ birthday banquet on $2^{\text {nd }}$ November 1891 in which he described how his most important new thoughts came to him:

"[Following] previous investigation of the problem in all directions...happy ideas come unexpectedly without effort, like an inspiration. So far as I am concerned, they have never come to me when my mind was fatigued, or when I was at my working table...they came particularly readily during the slow ascent of wooded hills on a sunny day" (Helmholtz quoted in Wallas, 1926, p.80; cited by Wallas from Rigano, 1923, p.267-268).

Wallas selected only this short extract from Helmholtz's speech, however the speech does contain other pertinent observations:

"An investigator, or an artist, who is continually having a great number of happy ideas, is undoubtedly a privileged being...I have often been in the unpleasant position of having to wait for lucky ideas... They often steal into the line of thought without their importance being at first understood; then afterward some accidental circumstance shows how and under what conditions they have originated... But to reach that stage was not usually possible without long preliminary work." (Helmholtz, An Autobiographical Sketch, in Cahan, 1995, p.389)

In a supporting footnote Wallas also quoted the French symbolist poet Remy de Gourmont (1858-1915): "My conceptions rise into the field of consciousness like a flash of lightning or the flight of a bird" (Wallas, 1926, p.80). From this brief expostulation Wallas discerned three stages in the formation of a new thought: (1) Preparation": "the stage during which the problem was "investigated in all directions"”; (2) Incubation: "the stage during which he [Helmholtz] was not consciously thinking about the problem"; (3) Illumination: "the appearance of the 'happy idea' together with the psychological events which immediately preceded and accompanied that appearance" (Wallas, 1926, p.80). It was from the more extensive writings of Poincare on this subject that Wallas was able to embellish the process and discern the now familiar four stages (see below).

\footnotetext{
${ }^{2}$ In keeping with Wallas I will retain the use of mixed upper and lower case for each of the four stages.
} 


\section{Poincaré and mathematical creation}

In addition to the three stages detected in Helmholtz's birthday speech Wallas used the writings of the great French mathematician and his near contemporary Henri Poincaré (18541912) to discern a fourth stage. Poincaré's account resonated with that of Helmholtz in so far as Wallas saw in it Preparation, Incubation, and Illumination. However Poincaré paid particular attention to the post-Illumination phase. Poincaré narrowed his focus of attention by concerning himself with mathematical discovery since in this the human mind "seems to take least from the outside world" acting "only of itself and on itself" thereby offering insights into what is "most essential" in the mind (Poincaré, 1908/1952, p.22). Wallas construed Poincaré's two greatest mathematical discoveries as coming to him after specific periods of Incubation: first, involving military service as a reservist; second, involving a journey "during which no conscious mathematical thinking was done" (Wallas, 1926, p.81). The period of Incubation was one in which "much unconscious mental exploration took place"; the outcome of this stage (Illumination) is not a "ready-made result" instead Incubation supplied a starting point (Wallas, 1926, p.81) for further work in the Verification stage.

The term Verification is borrowed directly by Wallas from Poincaré. The latter used it on three separate occasions in his own account of the process of mathematical creation that was first published in English translation in 1915 from the original French Le Raisonnement Mathématique (1908, emphases added):

\footnotetext{
"It is necessary to put in shape the results of this inspiration, to deduce from them the immediate consequences, to arrange them, to word the demonstrations, but above all is verification necessary" (Poincaré, 1908/1952, p.27)

"It usually happens that it [the illumination] does not deceive him [the mathematician], but it also sometimes happens, as I have said, that it [the illumination] does not stand the test of verification" (Poincaré, 1908/1952, p.29)
} 
“...we might hope to find the product ready-made upon our awakening, or again that an algebraic calculation, for example a verification, would be made unconsciously. Nothing of the sort, as observation proves." (Poincaré, 1908/1952, p.31)

These "inspirations, fruits of unconscious work" provided "a point of departure" for further calculations (Poincaré, 1908/1952, p.31). The period of conscious work that follows the inspiration verifies the results and deduces their consequences. Poincaré described three incidents involving the interplay of Illumination, 'impasse' (a term used by subsequent researchers but not in Poincaré's own account), and Verification.

First, he established the existence of a particular class of Fuchsian functions (the 'hyper-geometric series') as follows: "for fifteen days I strove to prove...I seated myself at my work table, stayed an hour or two, tried a great number of combinations and reached no results". Then one evening "contrary to [his] custom" Poincaré drank some black coffee "and could not sleep. Ideas arose in crowds; I felt them collide until pairs interlocked...making a stable combination". By the next day he had established the existence of the series and "had only to write out the results, which took but a few hours" (Poincaré, 1908/1952, p.25).

Second, he further described another moment of insight that occurred on a geological excursion which had made him "forget his mathematical work". The illuminative moment occurred this time as he stepped onto a bus: "At the moment when I put my foot on the step the idea came to me, without anything in my former thoughts seeming to have paved the way for it" (Poincaré, 1908/1952, p.26). At this point Poincaré made his first specific reference to the need for Verification: "I did not verify the idea; I should not have had time...taking my seat upon the omnibus" and continuing a conversation, but on his return home to Caen he "verified the result at [his] leisure" (Poincaré, 1908/1952, p.26). 
Third, a similar experience occurred after he went to spend a few days by the seaside, being vexed apparently at reaching an impasse to the extent that he was "disgusted" with his failure in the study of "some arithmetical questions" (Poincaré, 1908/1952, p.26). This break gave him the opportunity to think "of something else" (Poincaré, 1908/1952, p.26). Out walking one morning along a small cliff the insight came with a "brevity, suddenness and immediate certainty" (Poincaré, 1908/1952, p.26). He then described the process of working out the consequences of his discovery as a "perfectly conscious" process in which he "form[ed] all these functions", "made a systematic attack upon them", and "carried all the outworks, one after another". However this only served to "show me the difficulty" leading to yet another impasse; one question "still held out" (Poincaré, 1908/1952, p.26). The solution "suddenly appeared" to him as he was "going along the street" during his period of military service in Mont-Valerien (Poincaré, 1908/1952, p.26). And it was only after his service that arranged all the elements and put them together and was thereby able to write-out his "final memoir at a single stroke without difficulty" (Poincaré, 1908/1952, p.26). He confined his descriptions of these processes to the example of Fuchsian functions only. In so far as his other researches are concerned he maintained that he "would have to say analogous things" (Poincaré, 1908/1952, p.27) about them also.

One of the aspects of Poincaré's account of mathematical creation which does not manifest explicitly in The Art of Thought is the interplay between 'conscious work' and 'unconscious work'. For Poincaré Illumination is a "manifest sign of long unconscious prior work", moreover unconscious work is possible and "only fruitful" if it is preceded and followed by a period of conscious work. Sudden inspirations "never happen" unless they have been preceded by "fruitless" voluntary efforts which may not have been as "sterile" as they appear because "they have set agoing the unconscious machine" which, without conscious efforts, "would not have moved and would have produced nothing" (Poincaré, 
1908/1952, p.27). The first period of conscious work is Preparation; the second period of conscious work involves arranging, putting "in shape" and wording the inspiration, deducing its consequences, and its Verification (Poincaré, 1908/1952, p.27). Poincaré underlined the significance of this second bout of conscious work by noting that inspirations often are accompanied by "absolute certitude", and that this feeling is not usually "a deceiver" but this is not a rule that is without exception (Poincaré, 1908/1952, p.27). Certitude can deceive the discoverer "without being any the less vivid", and this fact may only become apparent when the discoverer seeks to demonstrate the findings (Poincaré, 1908/1952, p.27). As a postscript Poincaré noted in particular that ideas coming in the morning or evening "in bed while in a semi-hypnagogic state" can deceive, and they in particular must be put to the test of Verification (Poincaré, 1908/1952, p.27).

\section{Wallas' four-stage model}

Based largely but not exclusively on the accounts of Helmholtz and Poincaré, Wallas proposed four stages. The model presents a synthesis of the three stages of scientific discovery discernable from Helmholtz's $70^{\text {th }}$ birthday speech, the role of unconscious and conscious mental processes in mathematical creation, and the need for Verification as revealed in Poincaré's introspections.

Preparation and Verification: these stages 'book-end' the process. The mode of thought in Preparation is conscious, "voluntary" (Wallas, 1926, p.85) and "regulated" rather than a "wild ranging of the mind" (p.83). Wallas included logic, mathematics, experimental and observational sciences in Preparation. One of the ways Preparation might be achieved was through education which gives the 'educated man' "a body of remembered facts and words which gives him a wider range in the final moment of association, as well as a number of those habitual tracks of association which constitute "thought systems"” (ibid.). Following the same line of reasoning as Poincaré, Wallas argued that Verification resembles Preparation 
in so far as it is under conscious control and relies on the same mathematical and logical rules. Having circumscribed the model with the first and final stages Wallas then turned his attention to describing the second and third stages (Incubation and Illumination).

Incubation: for Wallas Incubation had both positive and negative attributes. Its 'negative' attribute was that during Incubation "we do not voluntarily or consciously think on a particular problem" (Wallas, 1926, p.86). Its 'positive' attribute was that "a series of unconscious and involuntary (or foreconscious and forevoluntary) mental events may take place" (ibid.). As for the first attribute Wallas argued that the abstention from mental work may take one of two forms, and described these as two forms of incubation as follows: "conscious mental work on other problems" (referred to in this article as 'distraction'); "relaxation from all mental work" (referred to in this article as 'mental relaxation') (Wallas, 1926, p.86). Incubation is a fertile resource for the creative thinker, therefore posing the problem in conscious thought (Preparation) as early as possible maximizes the amount time for 'extending' and 'enriching' the mental operations of subconscious thought. Wallas argued that the first form of incubation (distraction) was more effective for less difficult forms of creative thought (such as a preacher composing "his Sunday sermon", Wallas, 1926, p.86).

In the case of the more difficult forms of creative thought (such as "a scientific discovery", "writing of a poem", or a "political decision") it is more desirable that there be a period of total mental relaxation so that "nothing should interfere with the free working of the unconscious or partially conscious processes of the mind"( Wallas, 1926, p.87). Wallas cited the example of the theory of evolution through natural selection: the two pioneers of this revolutionary idea were forced into mental relaxation, Alfred Russell Wallace by malaria, and Darwin through unspecified 'ill-health'. Wallas reasoned that these misfortunes "compelled" (ibid.) both Wallace and Darwin to desist from mental activity and thereby engage 
involuntarily in Incubation. Wallas argued further that the mental relaxation required in Incubation may benefit from, or even require, physical exercise (as in both Helmholtz's and Poincaré's experiences) and that that "the human organism gains more from the alternation of various forms of activity than from a constant devotion to one of them" (Wallas, 1926, p.90). For Wallas these activities amounted to methods for what might be termed 'executive functions' for the management of Incubation, however the control of Illumination was acknowledged to be a much more difficult challenge.

Illumination: the Illumination stage is circumscribed by Wallas so as to "restrict it to [the] instantaneous [and unexpected] "flash"” representing the culmination of a "train of association" (Wallas, 1926, pp.93-94, emphasis added) ending with the "final 'flash' or 'click"' (ibid.). In most subsequent accounts that are based on Wallas' four-stage model Incubation is depicted as leading directly to Illumination. However, Wallas devoted no less than 12 pages (Wallas, 1926, pp.95-107) of his 'Stages of Control' chapter to the phenomenon of the 'fringe consciousness' - the Intimation - that links Incubation and Illumination. A close reading of The Art of Thought reveals Wallas' model to have five rather than four stages (Fryer, 2012; Lubart, 2001; Sadler-Smith, 2008), see Figure 2.

\section{[FIGURE 2]}

\section{Wallas' model: More than meets the eye?}

Close reading of Wallas' own account reveals a number of subtle and important distinctions not only between 'conscious' and 'unconscious' states (following Poincaré's different types of 'mental work'), but also between 'focal ("full luminosity") consciousness' and 'fringe (periphery) consciousness', see Figure 2. Wallas used the metaphor of the Sun to represent consciousness (the domain of Preparation, Illumination and Verification) and the Sun's corona to represent fringe consciousness (Intimation). He also made a number of prescient 
observations and intriguing speculations regarding the Intimations that inhabit the 'fringe' of consciousness. Fringe consciousness phenomena may last up to the flash of illumination or continue beyond it, however this is difficult for a subject to report on phenomenologically it since it is likely to be - pursuing Wallas' metaphor - 'outshone' by the full luminosity of Illumination. He offered the negative examples of Poincaré and Helmholtz who, he argued, had either forgotten or not noticed any fringe consciousness phenomena but failing to acknowledge that they may not have experienced any Intimations as such. But in support of the role of fringe consciousness he cited various authors and referred specifically to William James' introspections: "the dying echo of whence it [the idea] came to us", and "the halo or penumbra that surrounds and escorts [the image]" (William James, Principles, Vol. I, p.255 cited in Wallas, 1926, p.97).

Wallas' psychology is eclectic and draws in large part (especially in Chapter 3 of The Art of Thought) on associationism. He traced the concept of 'association' to Aristotle's psychology (Wallas was an Oxford Classics scholar), and used the concept of an 'association train' or 'train of associations' to describe the dynamical processes operating between consciousness and non-consciousness. Fringe consciousness manifests an awareness of an 'association-train' in a state of rising consciousness "which indicates that the fully conscious flash of success is coming” (Wallas, 1926, p.97). In support of this Wallas offered the account of a "high English civil servant" who related to him his personal experience that "I often know that the solution is coming, though I don't know what the solution will be" (ibid.). Wallas also cited the Belgian 'pedagogic psychologist' J. Varendonck's Psychology of Daydreams (the introduction to which was written by Sigmund Freud), Dewey and Wundt to provide supporting evidence for the role of Intimations in scientific discovery:

"When I became aware that my mind was simmering over something, I had a dim feeling which it is very difficult to describe; it was like a vague impression of 
mental activity. But when the association had risen to the surface, it expanded into an impression of joy" (Varendonck, 1921, p.282 cited in Wallas, 1926, p.97).

"a vague feeling of the unexpected, or something queer, strange, funny, or disconcerting" (Dewey, 1910, How We Think, p.74, Cited in Wallas, 1926, p.98)

"In diesem Sinn ist das Gefühl der Pionier der Erkenntniss" (In this sense, the feeling of the pioneer of knowledge) Wundt, 1893, cited in Wallas, 1926, p.98)

Wallas also associated the degree (or "grade") of consciousness involved in the creative process with visual and verbal imagery (see Wallas, 1926, p.61). He described lessconscious and fore-conscious states as being associated with increased occurrence of visual images, whilst in conscious mental work verbal processes are to the fore (Wallas, 1926, pp.70-73). His interpretations resonate with the experiences Einstein related in his letter to Jacques Hadamard: "The physical entities which seem to serve as elements in thought are certain signs and more or less clear images... Conventional words or other signs have to be sought laboriously only in a secondary stage" (Ghiselin, 1952/1985, pp.32-33).

Illumination (equivalent to 'insight', see Sternberg \& Davidson, 1995), by definition, is a singular moment (Wallas' 'flash' or 'click'), whereas Intimation is a manifestation of a 'rising train of association' which may 'ascend' towards the threshold of consciousness at different rates and therefore last for varying lengths of time. In so far as Wallas' objective for an improved 'art of thought' was concerned he maintained that there could be few people "who will not gain by directing their attention from time to time to the feeling of Intimation, and by bringing their will to bear upon the cerebral processes which it indicates", in Varendonck's words “foreconscious processes for conscious ends" (Wallas, 1926, p.101).

One of the 'singular achievements' that Wallas was interested in was 'poetical expression'. He offered Shakespeare's description of the poet's work as spoken by Theseus in Act V, Scene 1 of A Midsummer Night's Dream as an illustration the relationship between Intimations and Illuminations (p.102): 
"And as imagination bodies forth

The forms of things unknown, the poet's pen

Turns them to shapes and gives to airy nothing

A local habitation and a name." (William Shakespeare, A Midsummer Night's

Dream)

Wallas, fascinated as he was with the control of Intimations and other forms of thought, was keen also to offer advice to the thinker. He looked to the final verse of Robert Graves' poem 'A Pinch of Salt' for guidance on how to balance the competing demands of Intimation and Illumination (p.103):

"Poet, never chase the dream.

Laugh yourself and turn away.

Mask your hunger, let it seem

Small matter if he come or stay;

But when he nestles in your hand at last,

Close up your fingers tight and hold him fast" (Robert Graves, A Pinch of Salt, 1916-17)

The delicate and ephemeral nature of Intimations present the creative thinker with three challenges (Wallas, 1926): first, letting the train of conscious arise as naturally as possible and not interfering too much in the process before the idea is as well-formed as possible (similar to the hypnagogic state [between wakefulness and sleep] in which the German chemist Kekulé claimed to have experienced in his discovery of the ring structure of benzene, see Boden, 2004; also in 'lucid dreaming', see Sparrow \& Thurston, 2010); second, capturing the essence of Intimation so as to guard against it drifting away or being supplanted (as in Coleridge's unwanted 'visitor from Porlock' who interrupted the poet's creative Intimations during the writing of the unfinished Kubla Khan); third, trying to put into words thoughts which "are so elusive that to attempt to articulate them is to scare them away, as a fish is scared by the slightest ripple" (Wallas, 1926, p.105). Wallas nonetheless acknowledged that sooner or later it is necessary "to make the conscious effort of expression" and thereby make "permanent his [or her] thought for the use of others" (Wallas, 1926, p.106). Indeed Helmholtz, a seminal influence in the development of Wallas' model, remarked that "I have 
always so turned my problem about in all directions that I could see in my mind its turns and complications, and run through them freely without writing them down (Helmholtz, An autobiographical sketch, in Cahan, 1995, p.389).

\section{Theoretical and Evidential Implications}

A close reading of Wallas' Chapter 4 ('Stages of Control') offers compelling grounds for the clear delineation and acknowledgement of Intimation as a linking stage between Incubation and Illumination in the creative process. In doing so a 'Five-Stage Model of the Creative Process' is to be preferred over the traditional four-stage interpretation. The model as depicted in Figure 3 is based on a close, first-hand reading and interpretation of Wallas' account. The model has three levels and five stages. The three levels are organized in terms of proximity to consciousness (or "grades of consciousness", Wallas, 1926, p.61).

Preparation and Verification are achieved voluntarily and effortfully through conscious work, whereas Incubation is achieved involuntarily and effortlessly through non-conscious work and is not open to introspection. Intimation occurs in the fringe of consciousness zone and is amenable only partly to attention and influence.

\section{[FIGURE 3 HERE]}

Previous developments of Wallas' four-stage model have developed novel interpretations for specific purposes, augmenting and adapting the model, and transcending Wallas' original conceptualization (e.g. Cropley \& Cropley, 2012). By going to the original source (The Art of Thought) this article re-presents Wallas' original model giving due emphasis to the Intimation stage. The five-stage process as presented here is consistent both with Wallas' own model of creativity and with the writings of the seminal figures on whose work he drew for inspiration (chiefly Helmholtz and Poincaré). Although Wallas' model is not a theory of creativity, it affords creativity researchers a unifying framework and general 
conceptual architecture within which relevant concepts and theories from creativity research may be positioned, some of which are specified in Table 1 .

\section{[TABLE 1 HERE]}

Preparation is dependent on domain-specific knowledge. Domain expertise (see Ericsson et al., 2007) forms the cognitive substrate for creativity; for example Cropley (2006) argued that if the French physicist Becquerel had not already been immersed deeply in relevant research he could not, by the chance coming together of uranium salts and photographic paper in a drawer, have discovered radioactivity, cf. Pasteur's aphorism 'chance favors the prepared mind'. Creative individuals often endeavor to solve open-ended problems by drawing on information from the problem's home domain but may also procure important knowledge from other seemingly unrelated source domains either through deliberate scanning or serendipity, for example, Charles Darwin's (a biologist) reading of T.R. Malthus' (a political economist) An Essay on the Principle of Population (1798) which contributed to the creative insight leading to the theory of evolution through natural selection (Gruber, 1995). Csikszentmihalyi and colleagues delineated ‘domain' (i.e. cultural/symbolic system of rules and behaviors which determine what is permissible within its boundaries) from 'field' (see 'Verification' below). Domain and field are inter-related aspects of the socio-cultural environment in which creativity is located (Csikszentmihalyi, 2006;

Csikszentmihalyi \& Sawyer, 1995). The symbolic resources of the domain determine what is intellectually and creatively possible. The mastery of the domain enables Preparation.

Incubation serves a guiding function to the extent that clues that reflect and ultimately reveal coherence automatically activate relevant networks in a gradual and cumulative fashion by a neural process of 'spreading activation' (Bowers et al., 1990) involving the collective co-spiking of neurons "referred to as neural cliques" (Gabora \& Ranjan, 2013, 
p.28, original emphases). Simonton (1999), in a review of experimental, psychometric and historiometric evidence, argued that the creative process itself is 'Darwinian' in that blind variation and selective retention play vital roles in a generic creative process. Both spreading activation and blind variation/selective retention are captured in Wallas' Incubation stage. More recently Dijksterhuis and colleagues have proposed an Unconscious Thought Theory (UTT) which also resonates with Wallas' incubation stage in that it proposes that "contrary to conventional wisdom, it is not always advantageous to engage in thorough deliberation before choosing" and that 'unconscious thought' has a "generative power" with respect to creative cognition and complex decision making (Dijksterhuis \& Meurs, 2006, p.1005).

Wallas' Intimations bear a strong resemblance to creative intuitions defined variously as: (1) "a vague anticipatory perception that orients creative work in a promising direction", Policastro (1995, p. 99); (2) "Feelings that arise when knowledge is combined in novel ways" (Dane \& Pratt, 2009, p.5); (3) "slow-to-form affectively-charged judgments occurring in advance of an insight that combine knowledge in novel ways based on divergent associations, and which orient behavior in a direction that may lead to a creative outcome" (Gore \& Sadler-Smith, 2012, p.308). Intimations also share similarities with the phenomenon of 'feelings of knowing' (see: Koriat \& Levy-Sadot, 2001) and the neural mechanisms for “creative intuitions" discussed by Thagard (2014, p.287).

Both Intimation and Illumination are elusive phenomena. Nonetheless, neurophysiological and neuroimaging studies are beginning to offer preliminary biological evidence for a number of neural correlates of these processes. The key findings from Dietrich and Kanso's (2010) critical review of this field may be summarized thus: (1) contrary to conventional wisdom Illuminations are not generally associated with right hemispheric dominance; (2) Illumination is associated with decreased alpha power; (3) the superior temporal gyrus (STG) plays some role in solving insight problems that require 
verbal trains of associations; (4) activation in the anterior cingulate cortex (ACC) is associated with insight problem solving; (5) the role that the prefrontal cortex plays in Illumination is as yet unclear with the possibility that "both prefrontal activation and deactivation are at work" each being "associated with its own types of insight experience" (p.844). For a further review of cognitive neuroscience and creativity see Sawyer (2011)

Finally, Verification takes place within the socio-cultural environment instantiated in Csikszentmihalyi's concept of 'field'. The field is made up of expert individuals who practice in the domain and represent the social organization of the domain and embody its rules. These are enacted by the members of the field (e.g. critics, curators, grant awarding bodies, peer reviewers, journal editors, prize committees, investors, venture capitalists, etc.) who act as 'gatekeepers'. Creative insights do not exist in a vacuum because their Verification is culturally and historically bound to traditions and social structures (Amabile, 1996, p. 37).

A further, less well-trodden path in creativity research which Wallas draws our attention to from his reading of Poincaré's account of mathematical discovery is the role of sensibilité in the creative process. Sensibilité is an ambiguous term which may be translated as 'feelings' or 'sensibility' its function is to act as a "selective force" playing the role of a “delicate sieve" (Poincaré, 1908/1952, p.29) which enables the selection of the "apparently right solution" whilst rejecting the "apparently wrong solution" (Wallas, 1926, p.75). Poincaré's own account concerned how the "interesting" combinations formed as a result of the "automatism of the subliminal [unconscious] self" "break into the domain of consciousness" (Poincaré, 1908/1952, p.28). Poincaré does not attribute this breaking-though to chance, rather it is as a result of the strength of the accompanying affect which leads to "only the most intense [experiences]" influencing "our emotional sensibility", furthermore this process is linked to the aesthetic feeling for the beauty of the harmony and form of 
numbers that all "real" mathematicians know (Poincaré, 1908/1952, p.29). Wallas described this emotional sensibility for mathematical beauty as "aesthetic instinct" (Wallas, 1926, p.76). Poincaré described it as those creations whose elements are "harmoniously disposed so that the mind without effort can embrace their totality while realizing the details...The useful combinations are precisely the most beautiful" (Poincaré, 1908/1952, p.29).

A further aspect of sensibilité in Poincare's account is the intuiting of a 'mathematical order" that enables the mathematician to "divine hidden harmonies and relations" by means of "a glance [at] the reasoning as a whole" (Poincaré, 1908/1952, p.24). Moreover, these harmonious relations protect the mathematician from forgetting vital elements in the manifest order of things because eventually as this order unfolds "each of them [elements] will take its allotted place in the array". Poincaré went on to argue that without this "delicate feeling" an understanding of higher mathematics will be unattainable, and this "special intuition" (possessed by individuals to greater or lesser extents) confers mathematical creativity on those who have it (Poincaré, 1908/1952, p.24). Several intuition researchers have drawn attention to the role played by affect in creative intuitions (e.g. Dane \& Pratt, 2009) and the productive relationship between 'intuitive awareness' and creativity (Sadler-Smith \& Shefy, 2007)

Poincaré's emphasis on 'sensibility' resonates with that of the English theoretical physicist and Nobel Laureate Paul Dirac (1902-1984). For Dirac it was "more important to have beauty in one's equations than to have them fit experiment...It seems that if one is working from the point of view of getting beauty in one's equations, and if one has really sound insight, one is on a sure line of progress" (Dirac, 1963, p.47) (in the same Scientific American article Dirac also speculated that "God is a mathematician of a very high order"). Dirac's contentions are not uncontentious; for example Simonton expressed the view that "no scientist would ever be so bold as to justify a theory on so irrational a basis 'beauty"' (1988, 
p.193). Nevertheless, these various arguments point towards a promising line of inquiry that might lead eventually to the delineation of an 'aesthetic intuition' (see Wild, 1938 for an early exposition of this concept) as an a-rational (as opposed to irrational, cf. Simonton above) component in creative problem solving. Aesthetic intuition may have relevance to scientific and artistic creativity alongside other types of intuition such as the problem-solving, expert, and creative intuitions identified by Dane and Pratt (2009) and Osbeck and Held (2014).

Wallas' Art of Thought is essentially a pragmatic book concerned with the improvement of thinking. Several suggestions for enabling and enhancing creative thinking stem from Wallas' five stages. Distraction, mental relaxation, and physical exercise help to control Incubation and facilitate Illumination. Becoming more aware phenomenologically of sensibilities and creative intuitions as they arise focuses attention on Intimations. Dunn et al. (2010, p.1842) raise the intriguing possibility that there may be individual differences in the ability perceive the "subtle bodily changes" which mark intuitions interoceptively. The art of creative thought requires a fine balance between Preparation through deep immersion in the domain, creating the conditions for Incubation to proceed, allowing Intimations to arise as naturally and freely as possible, capturing their essence without interfering with their progress towards the final Illuminative moment, and the objective and aesthetic Verification of the creative value of final outcome.

Directions for further research are suggested. For example, Wallas himself recommended that it would be interesting to examine the "biographies of a couple of hundred original thinkers and writers" in order to examine the Incubation stage in more depth (1926, p.87). Aside of a small number of exceptions (e.g. Klein, 2013; Klein \& Jarosz, 2011; Thagard, 2014) investigations on the scale suggested by Wallas have yet to be conducted systematically. Such research could also be extended to test if and how intimations precede 
illumination (see Figure 1). A variety of research approaches are most likely to be required including phenomenological studies, historiometric analyses, studies of biographies, individual difference studies, and cognitive neuroscience studies. One of the main challenges that researchers face is the unpredictability of occurrence of intimations and illuminations; capturing these events as close as possible to their occurrence is the ideal, for example by using concurrent protocol analysis (Baldacchino, Ucbasaran, Lockett, \& Cabantous, 2014), diary methods, or mobile technology applications to enable subjects to record their interoceptions and introspections concurrently (Hodgkinson \& Sadler-Smith, 2011). It is hoped that as a result of specifying Wallas' model with greater detail and more fidelity than has previously been the case this article will enable creativity researchers to better understand the subtleties and nuances the interplay of consciousness, fringe consciousness, and nonconsciousness in the creative process, the dynamics of which constitute a modern interpretation of the 'art of thought'. 


\section{References}

Alvesson, M., \& Sandberg, J. (2011). Generating research questions through problematization. Academy of Management Review, 36(2), 247-271.

Amabile, T. M. (1996). Creativity in context. Boulder: Westview.

Baldacchino, L., Ucbasaran, D., Lockett, A., \& Cabantous, L. (2014). Capturing intuition through concurrent protocol analysis. In M. Sinclair (Ed.) Handbook of research methods on intuition. Cheltenham: Edward Elgar, pp.160-175.

Boden, M. (2004). The creative mind: Myths and mechanisms. London: Routledge.

Bowers, K. S., Regehr, G., Balthazard, C., \& Parker, K. (1990). Intuition in the context of discovery. Cognitive Psychology, 22(1), 72-110.

Cahan, D. (1995). Hermann von Helmholtz: Science and culture. Chicago: The University of Chicago Press.

Cropley, A. (2006). In praise of convergent thinking. Creativity Research Journal, 18(3), 391-404.

Cropley, D., \& Cropley, A. (2005). Engineering creativity: A systems concept of functional creativity. Lawrence Erlbaum Associates Publishers.

Cropley, D., \& Cropley, A. (2012). A psychological taxonomy of organizational innovation: Resolving the paradoxes. Creativity Research Journal, 24(1), 29-40.

Csikszentmihalyi, M. \& Sawyer, K. (1995). Creative insight: The social dimension of a solitary moment, In R. J. Sternberg \& J. E. Davidson (Eds.) The nature of insight (pp. 329-363). Cambridge MA.: The MIT Press.

Csikszentmihalyi, M. (2006). A systems perspective on creativity. In R. J. Sternberg (Ed.). Handbook of creativity (pp.313-335). Cambridge: Cambridge University Press.

Dane, E., \& Pratt, M. G. (2007). Exploring intuition and its role in managerial decisionmaking. Academy of Management Review, 32(1), 33-54. 
Dane E, \& Pratt M. G. (2009). Conceptualizing and measuring intuition: a review of recent trends" In G. P. Hodgkinson \& J. K. Ford (Eds.) International Review of Industrial and Organizational Psychology, 24, 1-40. Chichester, UK: John Wiley \& Sons.

Dewett, T. (2003). Understanding the relationship between information technology and creativity in organizations. Creativity Research Journal, 15(2-3), 167-182.

Dietrich, A., \& Kanso, R. (2010). A review of EEG, ERP, and neuroimaging studies of creativity and insight. Psychological Bulletin, 136(5), 822.

Dijksterhuis, A., \& Meurs, T. (2006). Where creativity resides: The generative power of unconscious thought. Consciousness and Cognition, 15, 135-146.

Dirac, P.A.M. (1963). The evolution of the physicist's picture of nature. Scientific American, 208(5), 45-53.

Dodds, R. A., Smith, S. M., \& Ward, T. B. (2002). The use of environmental clues during incubation. Creativity Research Journal, 14(3-4), 287-304.

Doyle, C. L. (1998). The writer tells: The creative process in the writing of literary fiction. Creativity Research Journal, 11(1), 29-37.

Dunn, B. D., Galton, H. C., Morgan, R., Evans, D., Oliver, C., Meyer, M., \& Dalgleish, T. (2010). Listening to Your heart: How interoception shapes emotion experience and intuitive decision making. Psychological Science, 21(12), 1835-1844.

Ellwood, S., Pallier, G., Snyder, A., \& Gallate, J. (2009). The incubation effect: Hatching a solution?. Creativity Research Journal, 21(1), 6-14.

Ericsson, K.A., Prietula M.J \& Cokely, E.T. (2007). The making of an expert. Harvard Business Review July-August, pp. 115-121.

Fryer, F. (2012). Some key issues in creativity research and evaluation as seen from a psychological perspective Creativity Research Journal, 24, 1, 21-28. 
Gabora, L. (2010). Revenge of the "neurds": Characterizing creative thought in terms of the structure and dynamics of memory. Creativity Research Journal, 22(1), 1-13.

Gabora, L. \& Ranjan, A. (2013). How insight emerges in a distributed, content addressable memory. In O Vartanian, A.S. Bristol, \& J.C. Kaufman, (Eds.). Neuroscience of creativity. Cambridge, MA.: MIT Press, pp.19-43.

Gallate, J., Wong, C., Ellwood, S., Roring, R. W., \& Snyder, A. (2012). Creative people use non-conscious processes to their advantage. Creativity Research Journal, 24(2-3), 146151.

Ghiselin, B (1952/1984) The creative process: Reflections on invention in the arts and sciences. Berkeley: University of California Press, pp.22-31.

Gore, J., \& Sadler-Smith, E. (2011). Unpacking intuition: A process and outcome framework. Review of General Psychology, 15(4), 304.

Gruber, H. E. (1995). Insight and affect in the history of science. In In R. J. Sternberg \& J. E. Davidson (Eds.) The nature of insight. Cambridge MA.: The MIT Press.

Healey, D., \& Runco, M. A. (2006). Could creativity be associated with insomnia? Creativity Research Journal, 18(1), 39-43.

Helmholtz, H. (1891/1995). An autobiographical sketch. In D. Cahan (Ed.). Hermann von Helmholtz: Science and culture. Chicago: The University of Chicago Press, pp.381-392 Hodgkinson, G. P., \& Sadler-Smith, E. (2011). Investigating intuition: beyond self-report. In M. Sinclair (Ed.) Handbook of intuition research, Cheltenham, Edward Elgar, pp.5257.

Horan, R. (2007). The relationship between creativity and intelligence: A combined yogicscientific approach. Creativity Research Journal, 19(2-3), 179-202.

Horan, R. (2009). The neuropsychological connection between creativity and meditation. Creativity Research Journal, 21(2-3), 199-222. 
Horng, J. S., \& Hu, M. L. (2008). The mystery in the kitchen: Culinary creativity. Creativity Research Journal, 20(2), 221-230.

Horng, J. S., \& Hu, M. L. (2009). The creative culinary process: Constructing and extending a four-component model. Creativity Research Journal, 21(4), 376-383.

Howard-Jones, P. A., \& Murray, S. (2003). Ideational productivity, focus of attention, and context. Creativity Research Journal, 15(2-3), 153-166.

Jalil, P. A. (2007). Working memory, cerebellum, and creativity. Creativity Research Journal, 19(1), 39-45.

Jung-Beeman M., Bowden, E.M., Haberman, J., Frymiare, J., Arambel-Lui, S., Greenblat, R., Reber, P.J., \& Kounios, J. (2004). Neural activity when people solve problems with insight, Public Library of Science (Biology), 2(4), 0500-0510.

Klein, G. (2013). Seeing what others don't: The remarkable ways we gain insights. New York: Public Affairs.

Klein, G., \& Jarosz, A. (2011). A naturalistic study of insight. Journal of Cognitive Engineering and Decision Making, 5(4), 335-351.

Koriat, A., \& Levy-Sadot, R. (2001). The combined contributions of the cue-familiarity and accessibility heuristics to feelings of knowing. Journal of Experimental Psychology: Learning, Memory, and Cognition, 27(1), 34.

Kristensen, T. (2004). The physical context of creativity. Creativity and Innovation Management, 13(2), 89-96.

Lubart, T.I. (2001) Models of the creative process: Past, present and future. Creativity Research Journal, 13(3-4), 295-308.

Mainemelis, C. (2002). Time and timelessness: Creativity in (and out of) the temporal dimension. Creativity Research Journal, 14(2), 227-238. 
Norlander, T., \& Gustafson, R. (1997). Effects of alcohol on picture drawing during the verification phase of the creative process. Creativity Research Journal, 10(4), 355-362.

Norlander, T., \& Gustafson, R. (1998). Effects of alcohol on a divergent figural fluency test during the illumination phase of the creative process. Creativity Research Journal, $11(3), 265-274$.

Orlet, S. (2008). An expanding view on incubation. Creativity Research Journal, 20(3), 297308.

Osbeck, L. M., \& Held, B. S. (Eds.). (2014). Rational intuition: Philosophical roots, scientific investigations. Cambridge University Press.

Pagel, J. F., \& Kwiatkowski, C. F. (2003). Creativity and dreaming: Correlation of reported dream incorporation into waking behavior with level and type of creative interest. Creativity Research Journal, 15(2-3), 199-205.

Patrick, C. (1937). Creative thought in artists. Journal of Psychology, 4, 35-73.

Penaloza, A. A., \& Calvillo, D. P. (2012). Incubation provides relief from artificial fixation in problem solving. Creativity Research Journal, 24(4), 338-344.

Poincaré, H. (1908/1952). Mathematical creation. In B. Ghiselin (Ed.) The creative process: Reflections on invention in the arts and sciences. Berkeley: University of California Press, pp.22-31.

Policastro, E. (1995). Creative intuition: An integrative review. Creativity Research Journal, 8(2), 99-113.

Rastogi, D., \& Sharma, N. K. (2010). Creativity under concurrent and sequential task conditions. Creativity Research Journal, 22(2), 139-150.

Runco, M. A. (2004). Creativity. Annual Review of Psychology, 55: 657-687

Runco, M. A. (2014). Creativity: Theories and themes: Research, development, and practice. Elsevier. London; Elsevier. 
Sadler-Smith, E. (2008). Inside intuition. Abingdon: Routledge

Sadler-Smith, E., \& Shefy, E. (2007). Developing intuitive awareness in management education. Academy of Management Learning \& Education, 6(2), 186-205.

Sawyer, K (2011). The cognitive neuroscience of creativity: a critical review. Creativity Research Journal, 23(2), 137-154.

Segal, E. (2004). Incubation in insight problem solving. Creativity Research Journal, 16(1), 141-148.

Simonton, D.K. (1988) Scientific genius: A psychology of science. Cambridge: Cambridge University Press, 1988.

Simonton, D. K. (1999). Creativity as blind variation and selective retention: Is the creative process Darwinian? Psychological Inquiry, 10(4), 309-328.

Sio, U. N., \& Rudowicz, E. (2007). The role of an incubation period in creative problem solving. Creativity Research Journal, 19(2-3), 307-318.

Sparrow, G. S., \& Thurston, M. (2010). The five star method: A relational dream work methodology. Journal of Creativity in Mental Health, 5(2), 204-215.

Sternberg R.J., \& Davidson J.E. (1995). The nature of insight Cambridge, MA.: The MIT Press.

Thagard, P. (2014). Creative intuition: How Eureka results from three neural mechanisms. In L.M. Osbeck \& B.S. Held (Eds.). Rational intuition: Philosophical roots, scientific investigations. Cambridge University Press, pp.287-306.

Vartanian, O., Bristol, A.S., \& Kaufman, J.C. (2013). Neuroscience of Creativity. Cambridge, MA.: MIT Press.

Wallas, G. (1926). The art of thought. London: Jonathan Cape.

Wild, K.W. (1938). Intuition. Cambridge: Cambridge University Press. 
Wallas' four-stage model: More than meets the eye?

Yeh, Y. C. (2004). The interactive influences of three ecological systems on R\&D employees' technological creativity. Creativity Research Journal, 16(1), 11-25. 


\section{Figures}

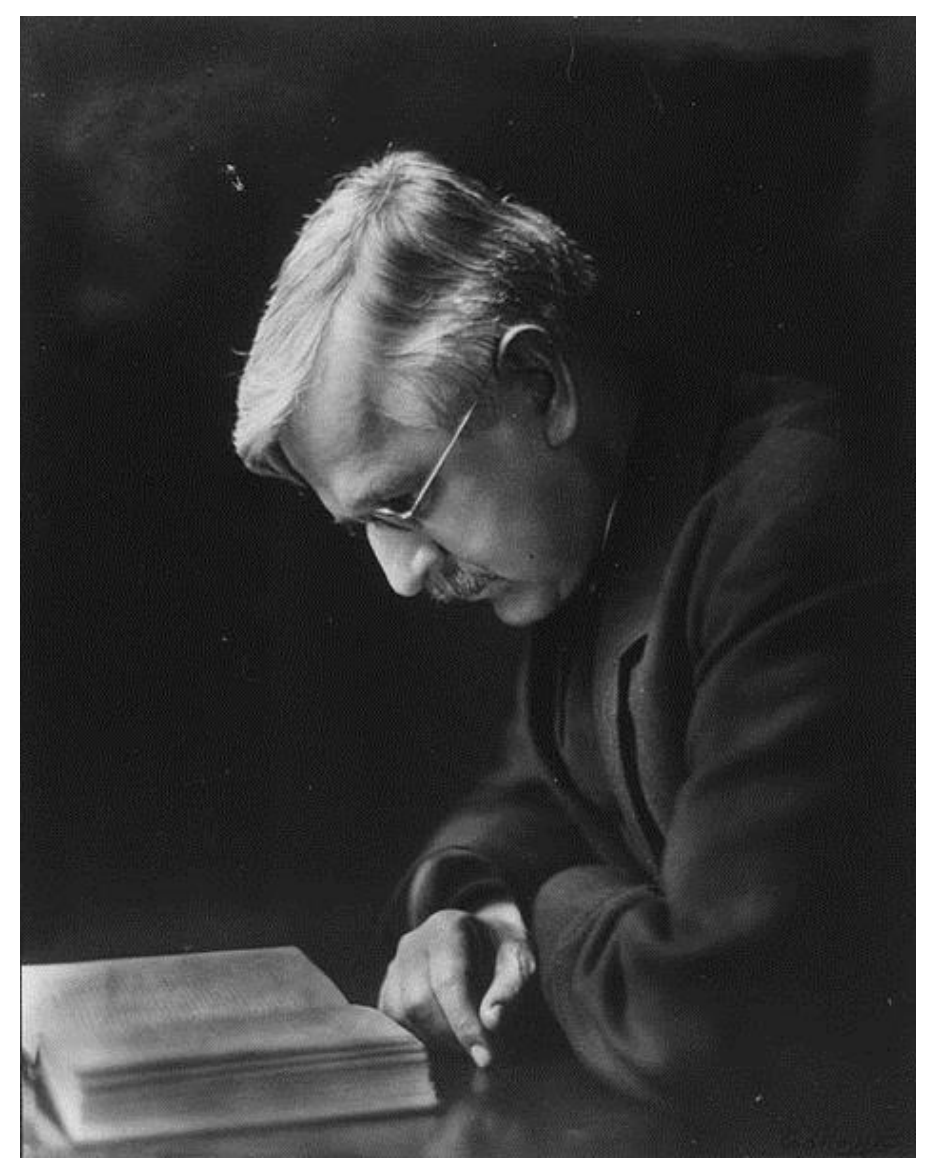

Figure 1. Graham Wallas deep in thought, circa 1920s (Reproduced by kind permission of

London School of Economics Library’s Collections, Imagelibrary/272) 
Figure 2. Five stages of the creative process

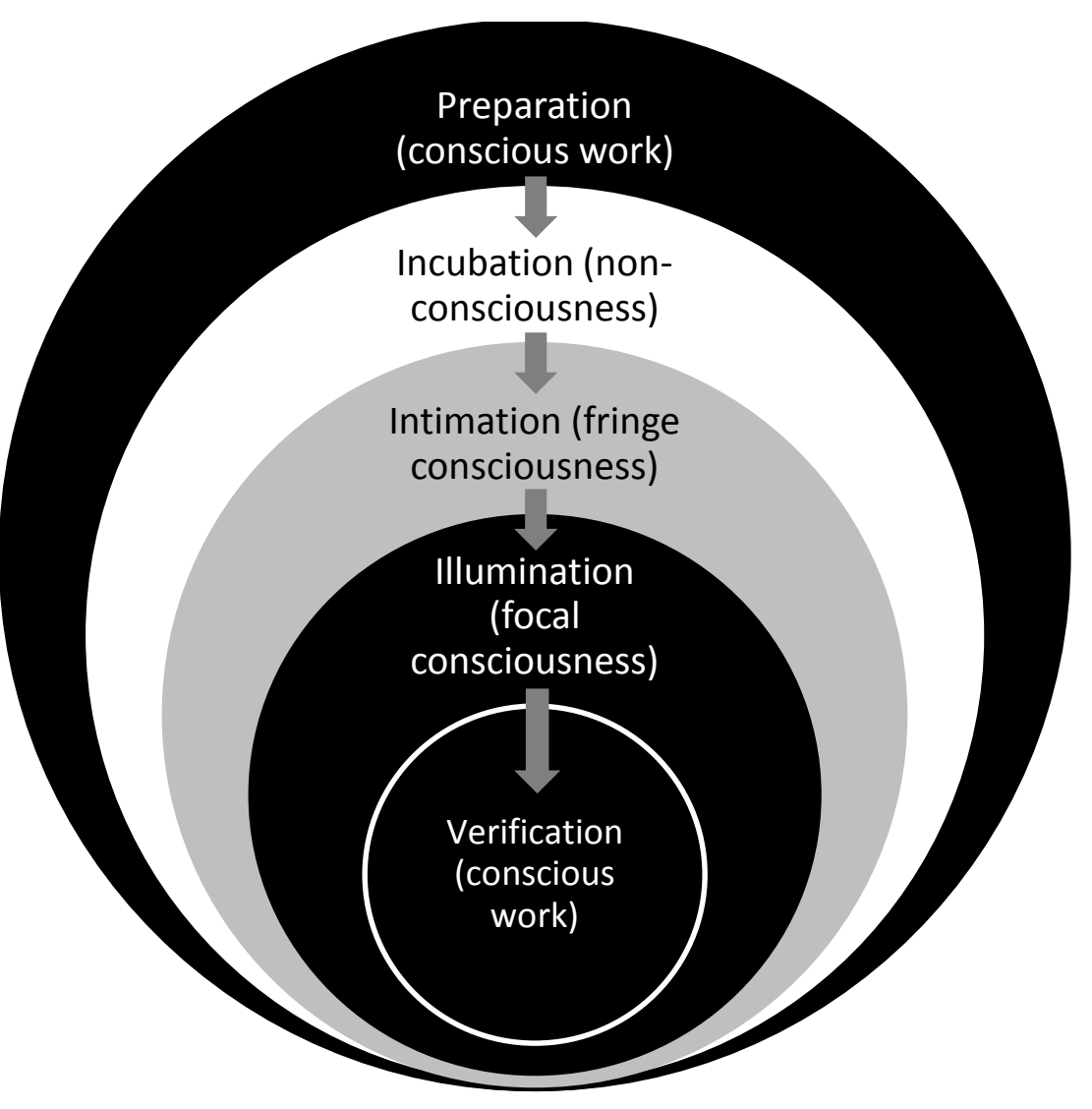


Figure 3. The creative process in terms of "grades of consciousness" (Wallas, 1926, p.61) (proximity to consciousness)

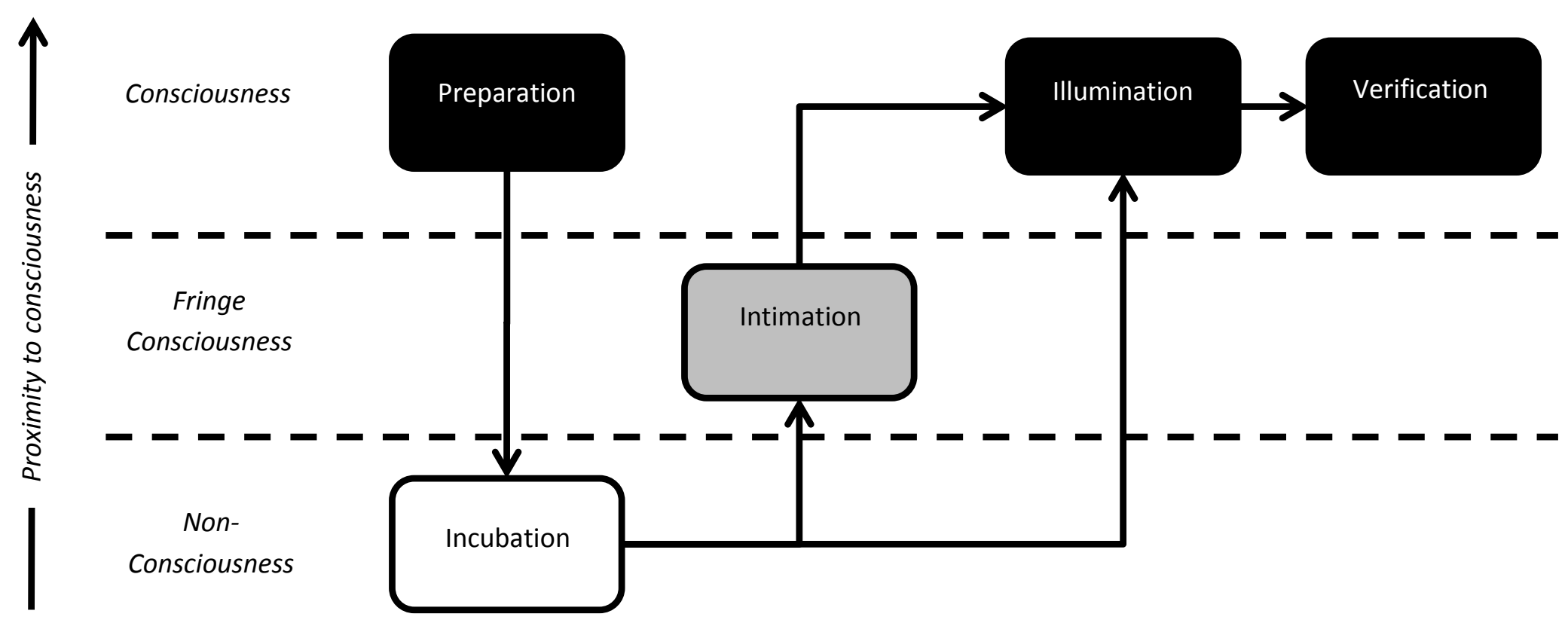


Table 1. Five-stage model mapped against related concepts and relevant sources

\begin{tabular}{|c|c|c|}
\hline Stage & Related Concepts & Relevant Sources \\
\hline \multirow[t]{3}{*}{ Preparation } & Domain & Csikszentmihalyi (2006) \\
\hline & Complex domain relevant schemas & Dane \& Pratt (2007) \\
\hline & Expertise & Ericsson et al. (2007); Klein, 2013 \\
\hline \multirow[t]{4}{*}{ Incubation } & Spreading activation & Bowers et al. (1990) \\
\hline & Unconscious thought theory & Dijksterhuis \& Meurs (2006) \\
\hline & Blind variation/selective retention & Simonton (1999) \\
\hline & Neural cliques and neurds & $\begin{array}{l}\text { Gabora (2010); Gabora \& Ranjan } \\
\text { (2013) }\end{array}$ \\
\hline \multirow[t]{2}{*}{ Intimation } & Creative intuition & $\begin{array}{l}\text { Dane \& Pratt (2009); Gore \& Sadler- } \\
\text { Smith (2011); Policastro (1995); } \\
\text { Thagard (2014) }\end{array}$ \\
\hline & Feelings of knowing & Koriat \& Levy-Sadot (2001) \\
\hline \multirow[t]{3}{*}{ Illumination } & $\begin{array}{l}\text { Anterior superior temporal gyrus } \\
\text { activation }\end{array}$ & Jung-Beeman, et al. (2004) \\
\hline & Neural cliques and neurds & $\begin{array}{l}\text { Gabora (2010); Gabora \& Ranjoan } \\
\text { (2013) }\end{array}$ \\
\hline & $\begin{array}{l}\text { Neural representation, recursive } \\
\text { binding, semantic pointer } \\
\text { competition }\end{array}$ & Thagard (2014) \\
\hline \multirow[t]{3}{*}{ Verification } & System & Amabile (1996) \\
\hline & Field & Csikszentmihalyi (2006) \\
\hline & Aesthetic intuition & Dirac (1963); Wild (1938) \\
\hline
\end{tabular}

